\title{
Hydrodynamic model of sedimentation and disinfection to predict water quality in water treatment plant
}

\author{
Euis Nurul Hidayah*, Okik Hendriyanto \\ Department of Environmental Engineering UPN “Veteran” Jatim, Surabaya, Indonesia
}

\section{Email address:}

euisnh@gmail.com (E. N. Hidayah),oqhc3@yahoo.com (O. Hendriyanto)

\section{To cite this article:}

Euis Nurul Hidayah, Okik Hendriyanto. Hydrodynamic Model of Sedimentation and Disinfection to Predict Water Quality in Water Treatment Plant. International Journal of Science, Technology and Society. Vol. 2, No. 4, 2014, pp. 73-77.

doi: $10.11648 /$ j.ijsts.20140204.13

\begin{abstract}
This current research used HPAs model for sedimentation process and HPAd model for disinfection process to make formulation of mathematical model of flow velocity, NFr and Nre patterns and to analyze the effect of hydrodynamic to contaminant. Transport mechanism in pollutant dispersion was analogized to pollutant transport phenomenon in river. This research aims to study mathematical models of velocity, $\mathrm{NRe}, \mathrm{NFr}$, E.coli distribution and residual chlorine patterns in baffle channel disinfection tanks based on the hydrodynamic model (HPAd Model) mathematical formulation and the suspended particles and turbidity in sedimentation tank based on the hydrodynamic model (HPAs Model). Research includes the formulation of mathematical models which results have been visualized by Mathlab, the acquisition of primary data using physical models, testing the model using Mathlab with the primary data input. The parameters flow velocity pattern (u), Reynolds numbers (NRe) and Froude numbers (NFr), but E.coli distribution and residual chlorine didn't influenced the pattern flow velocity and Froude Number. However, pattern flow had influenced turbidity and settling floc sedimentation. Dosage and type of disinfectant and coagulant influenced the pattern of Reynold Number due to effect of acceleration and dragging flow correlated to dispersibility.
\end{abstract}

Keywords: Sedimentation, Disinfection, Hydrodynamic, Modelling, Water

\section{Introduction}

Many factors can affect the performance and efficiency of water treatment, especially in the processing parameters are always fluctuating. For example, the decline turbidity parameters depend on the ability of combination treatment in coagulation, flocculation and sedimentation as well as the addition of coagulant. The mathematical model can be a good enough alternative to observe the hydrodynamics in a tub of water treatment. The mathematical model is constructed from two hydrodynamic equations, namely the continuity equation and momentum equation. Some of the models that have been studied are: empirical models [1], Flo ++ model [2]. FTCs (Flow Through Curves) can predict flow patterns and performance of the sedimentation basin [3]. Through CFD simulation models [4,5] and predict the distribution of particle deposition in a longitudinal sedimentation basin [6], HP2S Model [7]. This study aimed to constructd mathematical models through identifying the flow patterns associated with the sedimentation unit contains dissolved and suspended particles in the sedimentation basin, as well as identifying the flow patterns in the disinfection process associated with the E.coli. Both models will integrate with each other to form a mathematical model of the hydrodynamics of the water treatment in the Matlab programming language that can be used to predict the flow patterns and the patterns of change in pollutant concentration during the water treatment process.

\section{Materials and Methods}

\subsection{Optimizing Coagulant Dose and Disinfectant Dose)}

Jar test was the experimental methods to determine the optimum coagulant and disinfectant dose, which it used alum, poly aluminium chloride (PAC) and mixture of alum and $\mathrm{PAC}$ for coagulation and use $\mathrm{Ca}(\mathrm{OCl})_{2}$ and $\mathrm{Cl}_{2}$ as disinfectant. The experimental consist of a coagulation tank and flocculation tank both with turbine mixer, a rectangular sedimentation tank, flitration unit and disinfection tank. 


\subsection{Water Tretment Plant Laboratorium Scale Study}

Scaled physical models were based on a similarity theory, which used a series of dimensionless parameters that fully or at the least, partially characterize the physics. The choice of a scaling factor $n=L p / L m$, the present laboratory model has been designed with horizontal and vertical scales of $n_{h}=n_{v}=25$. The selected flow rates were selected to take into account the tank dimensions according to Reynolds (NRe) and Froude numbers (NFr). Runs were carried out with injection optimum coagulant dose for alum was $86 \mathrm{ppm}$, PAC $35 \mathrm{ppm}$ and mixture alum and PAC $70 \mathrm{ppm}$. If failure flocs was formed then must be selected flow rate again. For disinfectant dosage was setted up 0.1 to $0.5 \mathrm{mg} / \mathrm{L}$ with contact time 30 minutes. Finally, running carried out with flow rates $5 \mathrm{ml} / \mathrm{s}, 10 \mathrm{ml} / \mathrm{s}$ and $15 \mathrm{ml} / \mathrm{s}$.

\subsection{Identification Flowrate and Contaminant Ddistribution}

For identification of flow patterns, fluorescent was injected and the evolution of the color vein was observed. It is first step to the study hydrodynamic condition in sedimentation and disinfection tanks, so that the observed phenomena (recirculation, preferential flow paths, etc.) could be used as a qualitative orientation in the comparison of quantitative models. For identify of pattern, Smart Spectrophotometer took samples at 10 different points of surface basin into account turbidity in sedimentation and colour to represent hydrodynamic flow.

\subsection{Mathematical Formulation for Sedimentation and Disinfection}

Formulation for mathematical modeling based on formulation of mathematical in hydrodynamic model [7], which mathematical models are based on the law of conservation of mass, conservation laws and momentum transport phenomena. Results formulation was visualized with Mathlab program that obtained model flocs precipitation patterns and model E.coli distrubition in disinfection process.

\subsection{Mathlab Simulation}

Sedimentation process is known as HPAs model and disinfection process is known as HPAd, both were prepared with visualization by Mathlab program after changed axis y as width of river became axis $\mathrm{z}$ as depth of tank. Experimental data were used for simulation HPAs model. Next simulation conducted with length sedimentation tank variation to observed hydrodynamics condition. Outputs of running model were visualized in term of horizontal velocity flow, settling flocs pattern, turbidity, and NRe and NFr
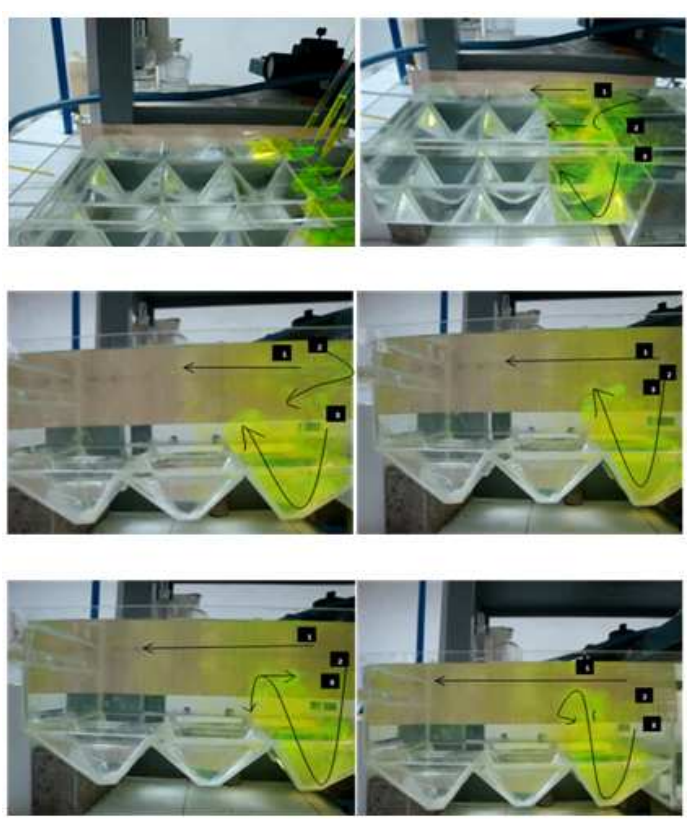

(a)
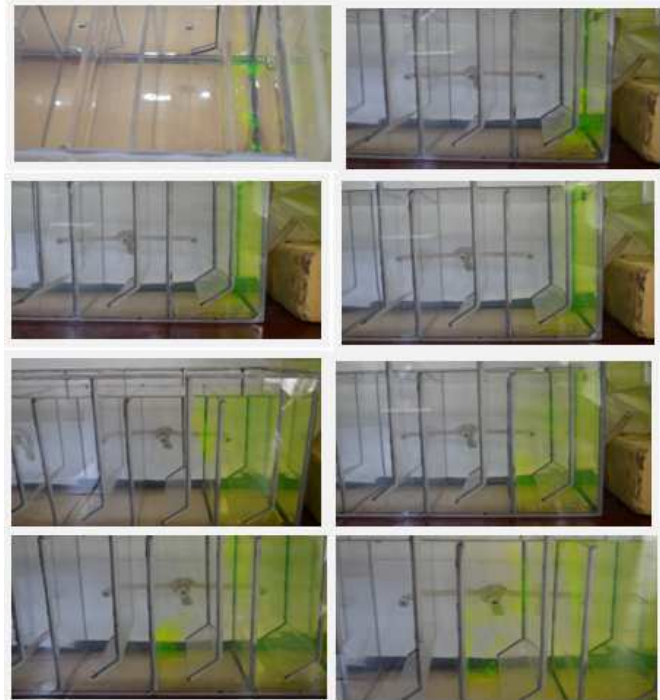

(b)

Figure 1. Flowrate pattern in identification contaminant dstribution (a) sedimentation (b) disinfection

\section{Results and Discussion}

\subsection{Identification Flowrate and Contaminant Ddistribution}

Figure 1 described schematically the observed paths with different flow rates in sedimentation tank. Figure 2 shows flowrate distribution in disinfection tank. Every flow rates variation has the same flow pattern, but velocity was varying alongside basin. In sedimentation, flow at first (1st) point was tends to move faster than the others, a backward flow was observed at the second (2nd) point, and a stagnant flow was observed at the third (3rd) point. In disinfection, flowrate tends to distribute slowly due to effect of baffle and 
distance each baffle [5]. In the bottom section of the tank, the above is mentioned currents form. These currents touch the bottom, where a backwards flow was observed. In general, the upper pass distributor such this experimental device caused the formation of a main current, at depth for low flow rates and in the upper regions for high ones. Several return currents were also noticed. NRe and NFr were the key parameters and it was their orders that were to be maintained. Since it was impossible to observe similarity according to both numbers at the same time, NFr was the most often considered, as it related to the inertia forces with the gravity forces [8].

\subsection{Implementation of Mathematical Formulation by using Mathlab}

Physical model with length of basin $=37.2 \mathrm{~cm}$ and depth $=$ $12 \mathrm{~cm}$ is used to identify the flow pattern, flow velocity measurements and the identification of patterns of settling. From the results of running by using physical models derived data, namely the horizontal flow velocity data, the value of turbidity at the starting point or sedimentation basin inlet. The other data consists of: dimensional basin, detention time, flow rates, flow rates of runoff, velocity injection. While the particle settling velocity of 0.025 $\mathrm{cm} / \mathrm{sec}-0.06 \mathrm{~cm} / \mathrm{sec}$ for the average particle diameter of 0.08 $\mathrm{mm}-0.85 \mathrm{~mm}$ obtained from the research data in Malaysia [6]. These data are input to run the model in Mathlab. Running the model for all points, it has 3 points in the inlet of the sedimentation tanks with various types of coagulant.

Output running HP2S model of horizontal flow velocity pattern $(\mathrm{u})$, the pattern of particle settling velocity $(\mathrm{w})$, the pattern of turbidity concentration (c) as a parameter to analyze the deposition of flocs. Output from running model are NRe showing laminar flow conditions and NFr, which indicates stable flow conditions. Based on the horizontal flow velocity measurements, obtained a linear relationship between horizontal flow velocity against $\mathrm{NRe}$ and the nonlinear relationship between horizontal flow velocity and NFr. The relationship will be strengthened through the precipitation pattern model by adding the influence of flocs concentration turbidity.

Visualization images running the model shows that the coordinate $(0,0)$ is the starting point or inlet sedimentation basin, where the $x$-axis represents the surface of the basin and the $\mathrm{z}$ axis is the depth. Visualization pictures show the settling zone starting from the inlet to the depth of the tub. Figure 3 is one of the results of running the model with the use of alum coagulant on flow rate 36 liters/hour.

Overall, the results of running with a variety of data showed settling flocs patterns in the sedimentation basin which explained that the zones of sedimentation (settling zone) starting from the inlet to the outlet there is a decrease of flow velocity pattern, NRe, NFr and the concentration of turbidity. In addition, decrease also occurred along with the depth of the settling basin zone [9]. As for the pattern of settling flocs velocity there was an increase from the inlet to the outlet and along with the depth of the basin.

\subsection{Model HPAs and HPAd Simulation Using Mathlab}

Figure 2 showed simulation of HPAs model with length basin variation to ensure that hydrodynamic conditions has same pattern to length basin constant. Behavior of hydrodynamics in rectangular settling basin was influenced by kinetic energy, which the biggest was on surface basin and dissipated along with length and depth of sedimentation basin [2]. Therefore, velocity became decrease and particles were heavier than water were tend to sink to the bottom of the tank thereby dragging fluid along. The movement of fluid in turn affected to the settling of particles.

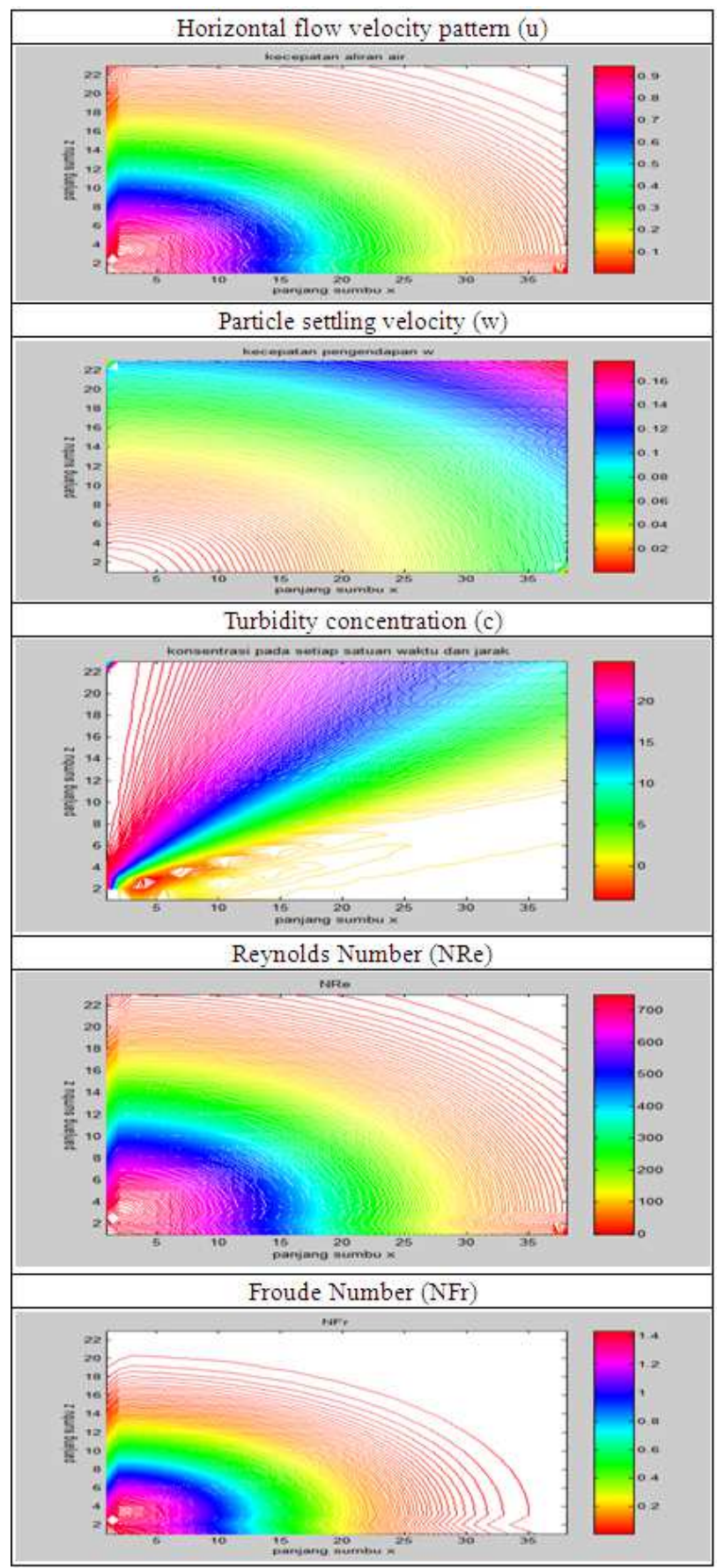

Figure 2. Visualization of mathlab program in sedimentation 
It was meant that $\mathrm{NRe}, \mathrm{NFr}$, turbidity decreased and settling velocity increased. Based on simulation model experimental, minimum velocity rate was $0.52 \mathrm{~cm} / \mathrm{s}$ with NRe values $<2000$ and NFr values $>1.10-5$ could removed turbidity $37.5 \%$ until $87.5 \%$ as initial value removal with various coagulants type. The particle settling velocity decreased with increased of turbulence intensity, but this tendency diminished when diameter got smaller that might be due to that the smaller particles settled down slowly for they were influenced more by turbulence than gravitation. When particle diameter was smaller enough, the particle tended to suspend and hardly to settle, no matter how intense the turbulence was [10].

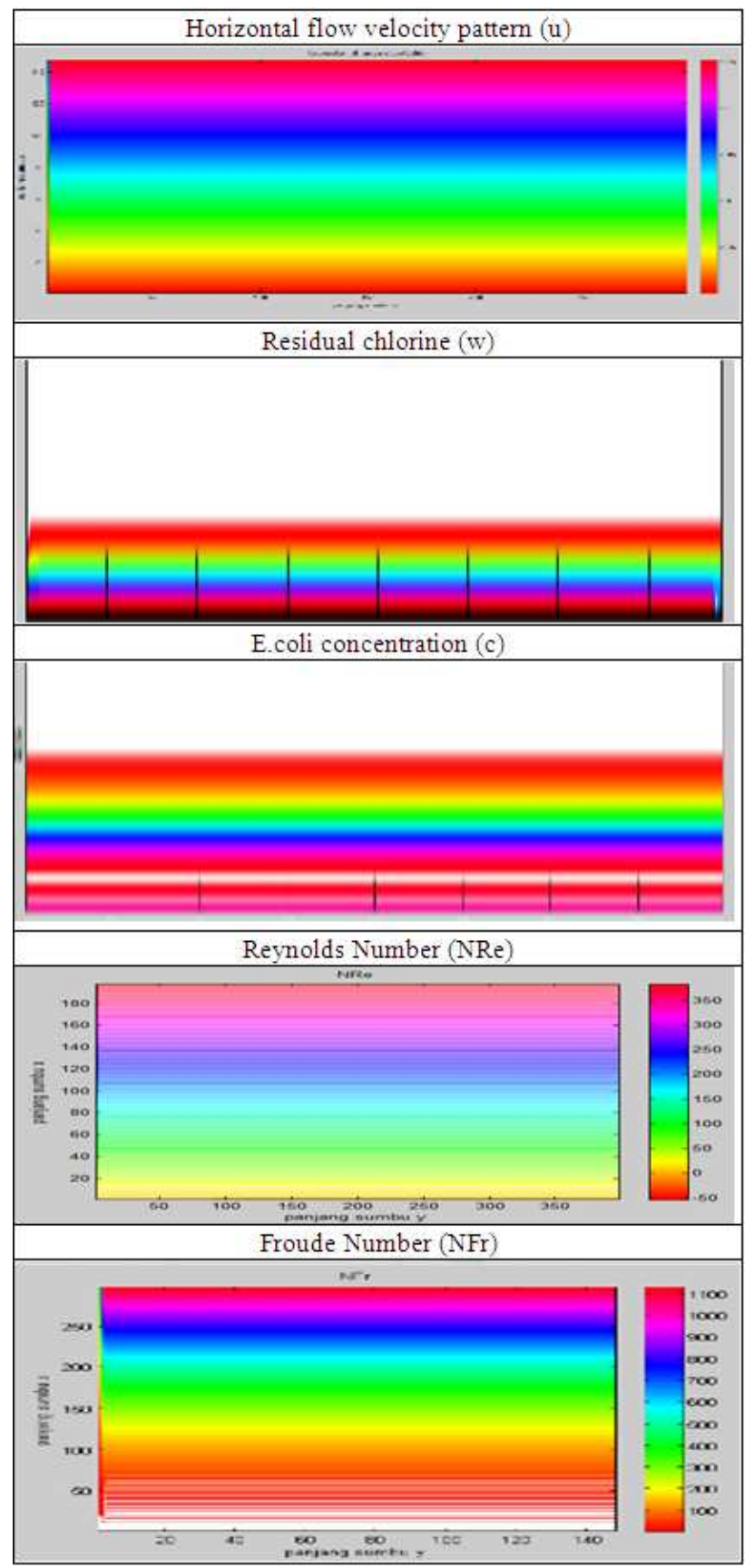

Figure 3. Visualization of mathlab program in disisnfection process
Fig. 3 indicates that the flow Froude Numbers changed slowly due to the influence of density, viscosity and the presence of dead or stagnant flow. The greater the flow, the more turbulent conditions. This suggests that the Reynolds Numbers is different in the beginning as a result of turbulence. Turbulence is a phenomenon that is not linear, three-dimensional and time-varying [2,6]. Due to disinfectant distributed well, then the disinfectant was able to eliminate E. coli or E. coli distribution decreases at high discharge. Different flow rates generated straight in the distribution pattern of E. coli in the watershed and curves of different areas. The flow rate affected the distribution pattern of residual chlorine as a result of differences in the velocity curves and straight flow area. Distribution of residual chlorine in turn is higher than in the straight stream, it is because of the smaller cross-sectional area curves and lack of motivation on the side wall of a straight flow, consequently there is a speed difference [10]. Different flow rates resulted in the distribution pattern of residual chlorine in the area and the straight flow curves of different areas.

\section{Conclusion}

Formulation of mathematical model of flocs precipitation patterns developed from HPAs model can be used in rectangular sedimentation tanks by using the parameters of the flow velocity pattern, the pattern of deposition velocity and concentration patterns of turbidity, Reynolds Numbers and Froude Numbers partially. Formulation of mathematical models of flocs precipitation patterns is still limited to the hydrodynamic model and settling flocs velocity model and flocculation model. Behavior of hydrodynamics in rectangular settling basin was influenced by kinetic energy.

Formulation of mathematical model of flocs precipitation patterns developed from HPds model can be used in disinfection baffle tanks by using the parameters as sedimentation tank. The pattern of horizontal flow velocity (u), Froude Numbers (NFR) and Reynolds Numbers (NRE) on the straight and turn with or without insulation and will be greatly influenced by the flow rate, where the greater the flow rate, the more turbulent conditions with a flow rate greater. Dose and type of disinfectant affected the pattern of Reynolds Numbers due to the influence of flow acceleration and shift correlated to dipersibilitas, and also affected the distribution pattern of E. coli and chlorine residual patterns as a result of the use of disinfectants to reduce E. coli and chlorine remaining after reacting with components other than E. coli.

Implementation of the HPAs model still in laboratory scale and the research will continue to validate the model by using pilot scale implementation, such as in water works.

\section{Acknowledgements}

This research was granted by Directory of Research and Community Service, Ministry of National Educatocial Republic of Indonesia No. 180/SP2H/PL/Dit.Litabmas/V/2013 


\section{References}

[1] G Matko, T.N., Fawcett, N., Sharp, A., Stephenson, T., Recent Progress in the Numerical Modelling of Wastewater Sedimentation Tanks, Process Safety and Environmental Protection 74(B4), 1997, p. 245-258

[2] Van der Walt, J.J., The Modelling of Water Treatment Process Tanks, Dissertation, University of Johannesburg, 2008

[3] Tamayol, A., Firoozabadi, B., Ahmadi, G., Determination of Settling Tanks Performance Using an Eulerian-Lagrangian Method, Journal of Applied Fluid Mechanics, Vol.1, No.1, 2008, p.43-54

[4] Razmi, A., Firoozabadi,B., Ahmadi, G., Experimental and Numerical Approach to Enlargement of Performance of Primary Settling Tanks, Journal of Applied Fluid Mechanics, Vol.2, No.1, 2009, pp.1 - 12.

[5] Athanasia, M.G., Margaritis, K., Thodiris, D.K., Anastasios, I.Z., A CFD Methodology for the Design of Sedimentation Tanks in Potable Water Treatment, Case Study: The Influence of a Feed Flow Control Baffle, Chemical Engineering Journal Vol.140, 2008, p.110-121

[6] Sammarraee, M.A., Chan, A., Salim, S.M., Mahabaleswar, U.S., Large-Eddy Simulations of Particle Sedimentation in a Longitudinal Sedimentation Basin of a Water Treatment Plant. Part I: Particle Settling Performance, Chemical Engineering Journal, 152, 2009, p. 307-314

[7] Karnaningroem, Nieke, Model Matematika Hidrodinamika Penyebaran Polutan di Sungai, Disertasi Program Pasca Sarjana ITS, Surabaya, 2006

[8] G. Ahmadi, A.B. Tamayol, B. Firoozabadi, Effect of inlet position and baffle configuration on the hydraulic performance of primary settling tanks, Journal of Hydraulic Engineering, ASCE 133-6, 2007, p.649-667

[9] J.F. Boyle, F.I Manas, L. Donald, Hydrodynamic analysis of the mechanisms of agglomerate dispersion, Powder Technology 1532 ,2005, p.127-133.

[10] L. Guo, D. Zhang, D. Xu, Y. Chen, An experimental study of low concentration sludge settling velocity under turbulent condition, Water Research 43, 2009, p.2383-2390. 